\title{
Conexiones más allá de la pantalla
}

\section{Connections beyond the screen}

\section{Roberto Torres Mandiola}

Museo de Ciencia y Tecnología de Chile, roberto.torresmandiola@gmail.com

\begin{abstract}
Resumen
En la actualidad la tecnología y el uso de herramientas digitales han permitido nuevas formas de relacionarse con las audiencias. Conscientes de esto, museos y espacios que promueven la cultura y el acceso al conocimiento, se han propuesto implementar nuevas medidas para estar presentes en las plataformas virtuales donde las personas interactúan a diario. Sin embargo, en muchos de estos casos, el centro de la comunicación continúa desarrollándose en el marco institucional, enfocándose en las actividades, exhibiciones o el valor patrimonial de las colecciones custodiadas por estas organizaciones. Es por esto que, a pesar de que hoy existen avances significativos en el acceso y las formas de comunicación, se hace aún más necesario profundizar en cómo transitar desde un paradigma hegemónico a una forma más abierta y colaborativa de creación, a través de comunidades que sean promotoras de las temáticas que abordan los museos. Siendo estas mismas quienes, desde su experiencia, generen nuevos contenidos usando sus propios lenguajes.
\end{abstract}

Frente a este desafio, el Museo de la Memoria y los Derechos Humanos de Chile, ha implementado algunas acciones digitales para compartir su archivo e historias, a través de formatos que desde su inicio se diseñaron priorizando la narrativa y la experiencia emocional, que estas acciones pueden llegar a generar en el público. Es el caso del proyecto Sintoniza con la Memoria, una galería auditiva online que también se transmitió por señal abierta de radio para revivir minuto a minuto el golpe de Estado en Chile, al cumplirse 45 años de este hecho. El día de su lanzamiento, la transmisión fue escuchada por más de 4 millones de personas.

Palabras clave: Narrativas digitales, activación de archivos, colecciones auditivas, estrategia digital, streaming, plataformas online.

\footnotetext{
Abstract

Today, technology and the use of digital tools have enabled new ways of relating to audiences. Aware of this, museums and spaces that promote culture
} 
and access to knowledge are implementing new ways to be present in the virtual platforms where people interact daily. However, in many of these cases, the center of communication continues to be institutional, focusing on activities, exhibitions or the heritage value of their collections.

This is why, even though today there are significant advances in access and the way we communicate, it is more necessary to go deeper into how to move from a hegemonic paradigm to a more open and collaborative form of creation, through communities that are promoters of the themes dealt with by the museums, these being the same who, from their experience, generate new content using their languages.

Faced with this challenge, the Museum of Memory and Human Rights of Chile has implemented some digital actions to share part of its collections, in formats that from the beginning were developed by prioritizing the narrative and emotional experience that these actions can generate with the public. This is the case of "The Memory Dial", an online audio gallery that was transmitted by open radio signal and that revived the coup d'état in Chile minute by minute on the 45th anniversary of this event. On the day of its launch, it was heard by more than 4 million people.

Keywords: Digital narratives, storytelling, archive activation, audio collections, digital strategy, streaming, online platforms. 


\section{Introducción}

Los museos son actores activos que inciden en la vida de las personas y también son espacios fundamentales para el desarrollo de la sociedad en su conjunto. A lo largo de la historia, estas instituciones han debido adaptarse a los cambios culturales de su entorno para poder relacionarse de mejor forma con su audiencia. Es así, cómo los museos han ido transitando desde una visión de custodios de los tesoros del pasado y conservadores de un patrimonio hegemónico, a lugares convencionales y abiertos a la creación de significados colectivos.

Estos cambios han ido de la mano del desarrollo tecnológico y las nuevas posibilidades que ofrece la era de la información y la digitalización; y es en este contexto donde surge el concepto de narrativas digitales y transmedia, introducido por el investigador estadounidense Henry Jenkins en 2003.

Relatar historias permite establecer vínculos entre el pasado, el presente y el futuro. Y de la misma forma, el uso de esta técnica discursiva puede dotar de una dimensión mucho más humana a los elementos que integran las colecciones de un museo, proporcionando un entendimiento más profundo del origen y el contexto de un objeto. Asimismo, la naturaleza universal que puede ofrecer un relato hace más accesible y cercana la relación con los contenidos que se están presentando.

En ese contexto, el uso de narrativas digitales se presenta como una alternativa frente a los esquemas relaciónales clásicos donde el experto o erudito entrega el conocimiento a un público receptivo y pasivo, desplazando esta comunicación vertical y jerárquica por múltiples instancias creadas para conectar emocionalmente.

En ese sentido, el académico español Carlos Scolari, también explica que las narrativas se convierten en un excelente recurso transmedia y se presentan como una posible solución ante la atomización de las audiencias. "El transmedia storytelling propone una experiencia común que abarca diferentes medios y dispositivos, todos ellos unidos por un hilo narrativo" (Scolari C., 2014, pág. 72).

\section{Discursos y nuevas plataformas}

A pesar de los cambios de paradigmas comunicacionales en la sociedad moderna, algunos museos aún continúan desarrollando acciones digitales a través de estructuras online "tradicionales" vinculadas a los inicios de la web. Los llamados repositorios son sistemas informacionales en los que los contenidos aparecen ordenados, organizados y estructurados según determinados criterios, y en los que prevalece la presencia del catálogo en línea. Estas estructuras se rigen por políticas de archivo y la lógica de la base de datos como método de organización de la información. Asimismo, su modelo narrativo constituye en sí un no-relato al estar basado en la individualidad del objeto, descrito en su ficha de registro estandarizada en un conjunto de metadatos. Son plataformas que pese a los avances que operan en el medio digital, se resisten a incorporar ciertos elementos más orgánicos y discursivos, persisten y se 
mantienen como trasfondo en la mayor parte de los proyectos digitales museísticos (Rodríguez, 2011).

En contrapunto, las nuevas narrativas digitales se muestran como prácticas de difusión con mayor impacto en la fidelización de públicos, como nuevos componentes para potenciar la interactividad con los visitantes y como recursos clave para la puesta en marcha de estrategias de acceso y compresión de las colecciones. Es así como el storytelling aprovecha las lógicas de participación social que definen el actual ecosistema digital. El uso de relatos como parte de las acciones culturales y el desarrollo de la comunidad virtual en redes sociales ha supuesto una transformación en museos impulsando prácticas de socialización que involucran una nueva mirada colectiva de su identidad y visiones aportadas por el conjunto de sus usuarios o visitantes. Visiones basadas en la emocionalidad, la afectividad y la subjetividad.

\section{Acciones que mueven a millones}

La siguiente experiencia ejemplifica cómo a través de la narrativa digital y el uso de nuevas tecnologías se pueden utilizar los archivos que forman parte del acervo de un museo para generar experiencias significativas.

Sintoniza con la Memoria es una acción digital que conmovió a millones de oyentes de todas partes de Chile y el mundo, que lograron seguir la transmisión radial del minuto a minuto del golpe de Estado en Chile, presentando los hechos tal como se vivieron el 11 de septiembre de 1973. Haciendo uso de la colección de archivos radiales del Museo, se creó esta galería auditiva que se transmitió por señal abierta de radio, por vía streaming desde redes sociales del Museo de la Memoria y desde el sitio web de la iniciativa: $\underline{\text { www.sintonizaconlamemoria.cl }}$

Tal fue el alcance de la acción, que logró ser escuchada por cerca de 4 millones de personas, y por su éxito, también fue incorporada a la pauta noticiosa de destacados medios nacionales, quienes compartieron parte de la transmisión en sus respectivos espacios por algunos momentos, generando debate y abriendo la reflexión nacional sobre ese hecho histórico que aún sigue latente.

El proyecto fue desarrollado por el equipo de comunicaciones del Museo de la Memoria junto con la agencia de publicidad Wolf BCPP y alcanzó reconocimiento internacional e importantes distinciones a nivel local en el ámbito del desarrollo social, diseño y creatividad. Dado su impacto e innovación en el uso del patrimonio auditivo histórico que resguarda el museo, esta acción se consolidó como una propuesta permanente de la conmemoración del 11 de septiembre.

\section{Objetivos}


A pesar de que los hechos ocurridos durante la dictadura civil-militar chilena son globalmente criticados, en Chile aún existen discursos negacionistas y figuras públicas que justifican el régimen militar y sus acciones, además de relativizar las violaciones de los derechos humanos cometidas durante el periodo. Es este grupo quien también intenta instalar la idea de que detenernos a reflexionar sobre los hechos del pasado no nos permite avanzar como sociedad hacia un bienestar común y que por el contrario, nos divide. Afirmación que va en directa oposición a lo recomendado por las Comisiones de Verdad chilenas y lo establecido en los principios de no-repetición de los organismos internacionales de derechos humanos.

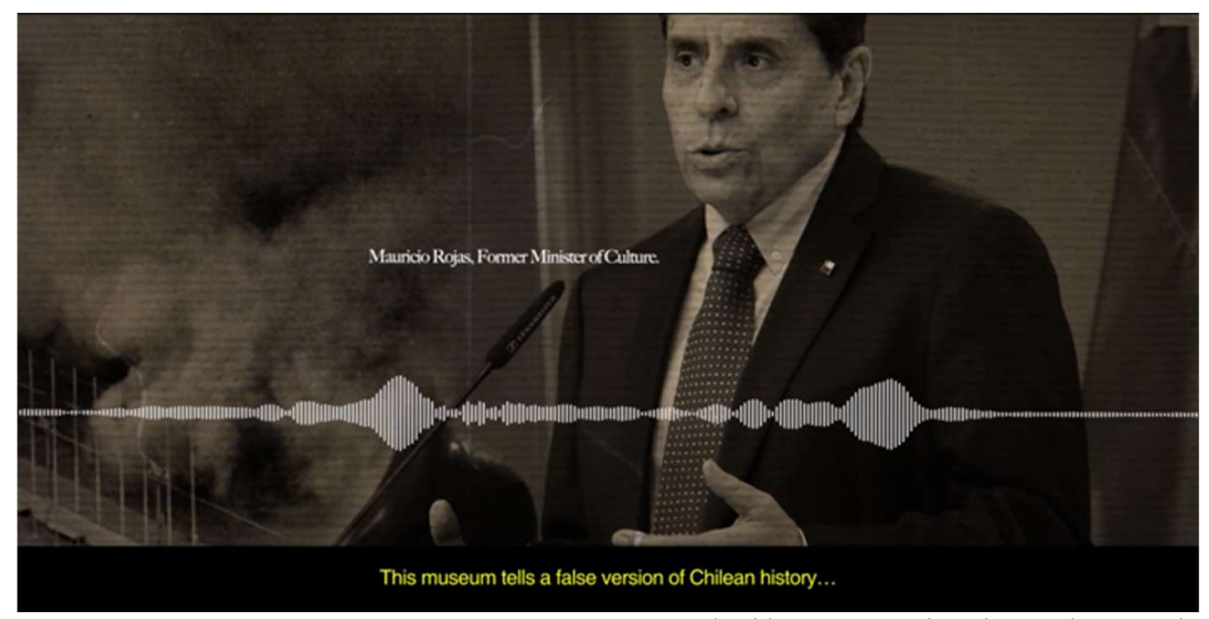

Fuente: Captura de video proyecto Sintoniza con la Memoria

Fig. 1 Imagen extracto de discurso de Mauricio Rojas, ex Ministro de Cultura del Chile

Frente a este contexto, uno de los objetivos principales de la acción fue generar una experiencia de memoria que presentara, desde una perspectiva más cercana, los hechos que vivieron miles de chilenas y chilenos durante la jornada del 11 de septiembre de 1973; dirigida especialmente a las nuevas generaciones. Y a partir de ese acercamiento hacia la historia, abrir un espacio para la reflexión nacional sobre la importancia del respeto por los derechos fundamentales y los valores democráticos como pilares sociales fundamentales, para no volver a repetir los errores del pasado. 


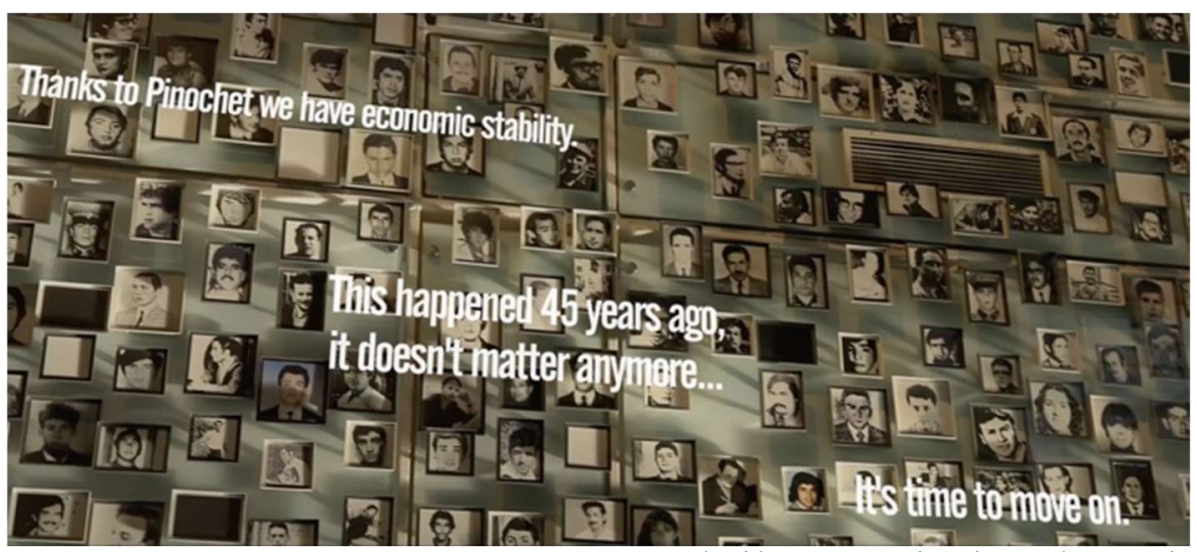

Fuente: Captura de video proyecto Sintoniza con la Memoria

Fig. 2 Algunos de los discursos que se expresan en medios sociales.

Por otro lado, esta activación también buscó poner en valor las colecciones de registros auditivos del archivo radial del museo, a través de una plataforma que los vinculara como parte de una experiencia sonora integradora que diera cuenta de los acontecimientos que formaron parte del desenlace del golpe de Estado chileno.

\section{Desarrollo de la innovación:}

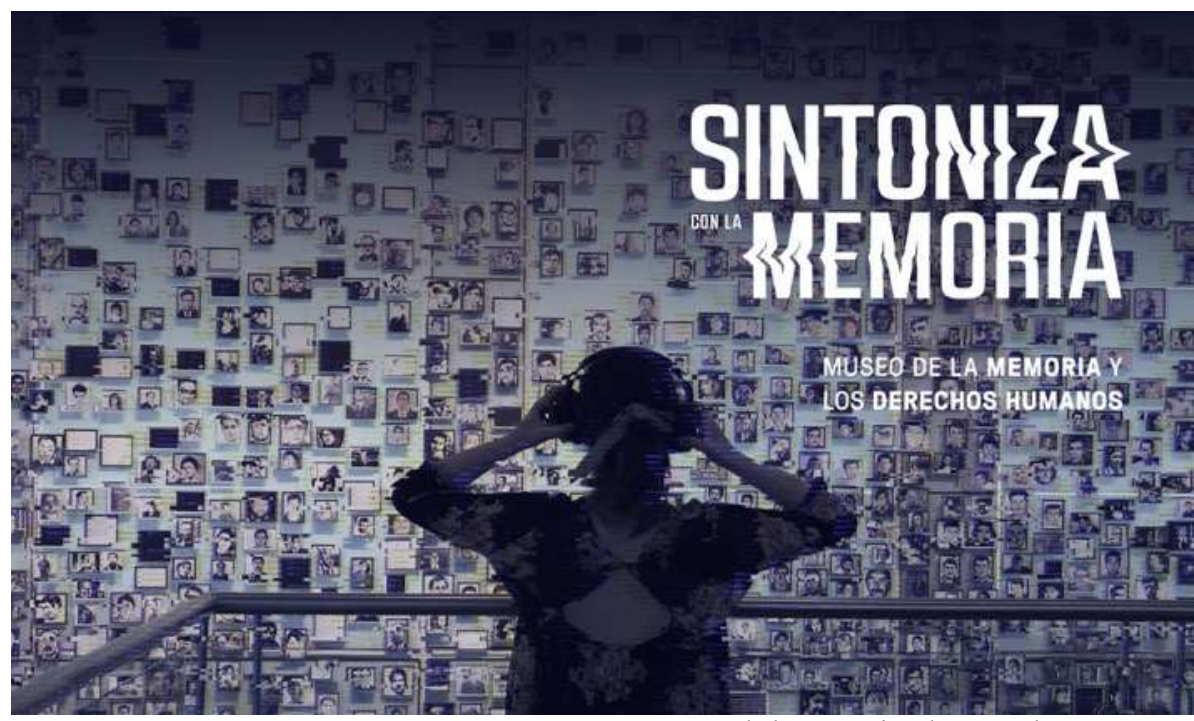

Fuente: Museo de la Memoria y los Derechos Humanos

Fig. 3 Gráfica de la campaña de la acción digital

En el marco de la conmemoración de 45 años del golpe de Estado en Chile, el Museo de la Memoria y los Derechos Humanos lanzó la experiencia digital Sintoniza con la Memoria, 
una galería auditiva en tiempo real que reconstruyó todos los sucesos del 11 de septiembre de 1973, a través de audios rescatados de la época que pertenecen al archivo radial que resguarda esta institución.

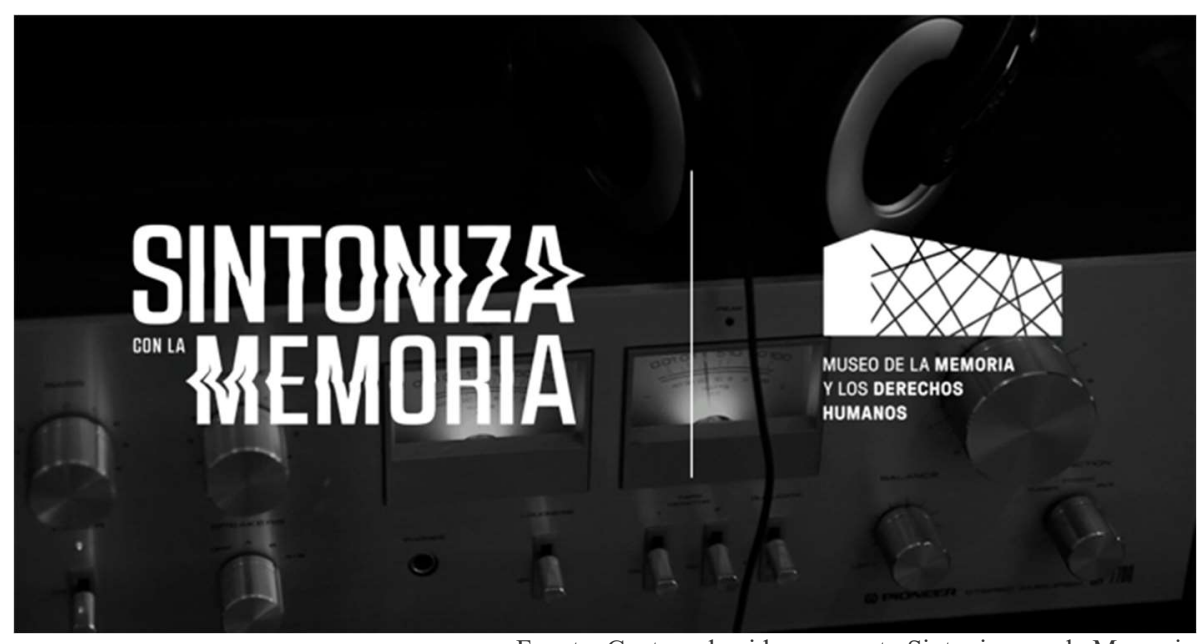

Fuente: Captura de video proyecto Sintoniza con la Memoria

Fig. 4 Logo de la acción digital

El Archivo, es una plataforma que reúne el acervo de audios radiales del museo, que corresponde a despachos periodísticos, noticias, segmentos, locuciones y programas completos; emitidos por radioemisoras nacionales e internacionales durante la dictadura civil-militar chilena. Es una plataforma dedicada principalmente a la investigación, que presenta su contenido en formato de base de datos.

Se utilizó este repositorio clasificado y categorizado para construir una plataforma online que, mediante una estrategia de narrativa transmedial, logró articular todos estos archivos en un relato unificado y experiencial, permitiendo reconstruir los eventos de tal forma que se sincronizaran cronológicamente y se escucharan a la misma hora en que ocurrieron en el pasado. En total, se utilizaron más de 557 archivos sonoros durante las 10 horas en que la transmisión estuvo al aire. 


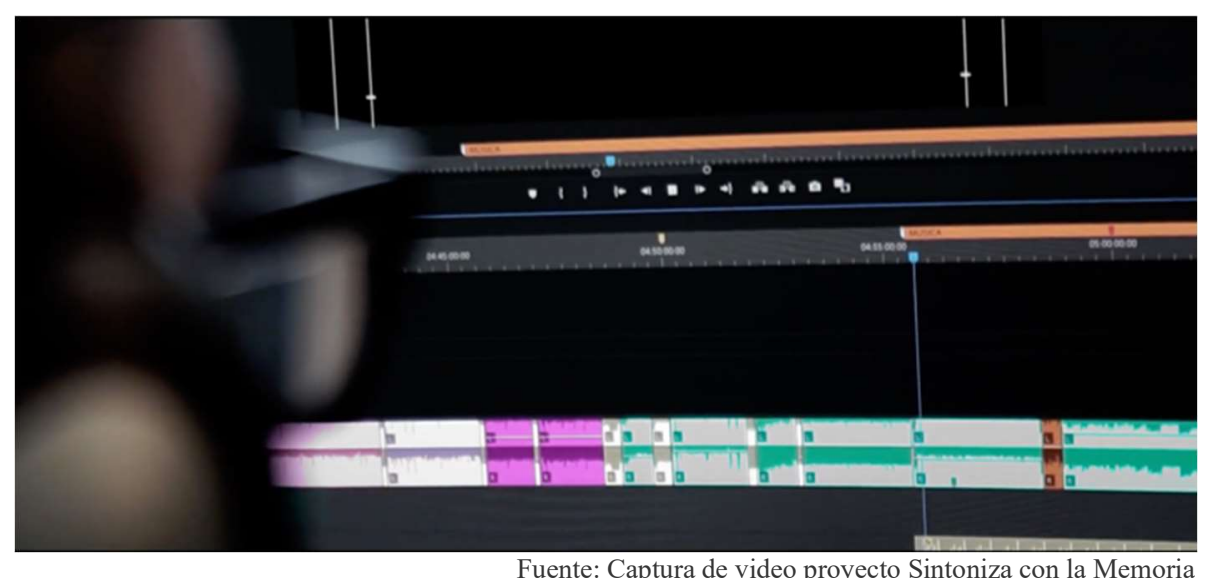

Fig. 5 Trabajo de edición de archivos sonoros. Cronología auditiva.

La transmisión minuto a minuto del desarrollo del golpe de Estado se realizó a través de la señal 690 AM de Radio Santiago y vía streaming en el sitio oficial del proyecto y las redes sociales del Museo de la Memoria.

El 11 de septiembre de 1973, a las 07:55 horas, Salvador Allende, que había llegado hace pocos minutos a La Moneda, anunciaba a través de radio Corporación y de la red "La Voz de la Patria" que un sector de la Marina se había tomado la ciudad de Valparaíso, en un acto que él mismo catalogó como un levantamiento contra el gobierno legítimamente constituido.

Las radioemisoras sintonizadas en dicha red hacían eco del llamado a la calma y a la serenidad de Allende. Radio Porteña AM, de Valparaíso, había sido tomada muy temprano por oficiales de la Marina, siendo una de las primeras estaciones en ser silenciada.

En este escenario, la radio fue el único medio de comunicación en registrar las primeras señales golpistas, entregando información que tiempo después se convertiría en parte importante del patrimonio político y cultural del país.

La transmisión inició a las 8:00 AM con audios históricos que fueron narrando cronológicamente los acontecimientos ocurridos durante aquel día que marcó la vida de miles de chilenas y chilenos. Bandos militares, comunicaciones militares secretas, el último discurso del presidente Salvador Allende y la cobertura en directo del bombardeo al Palacio de La Moneda, fueron parte de esta línea de tiempo radiofónica, que, sin interrupciones, acompañó a las y los auditores hasta las 18:00 hrs., para concluir con el discurso de los integrantes de la Junta Militar que daba inicio a los 17 años del régimen militar. 


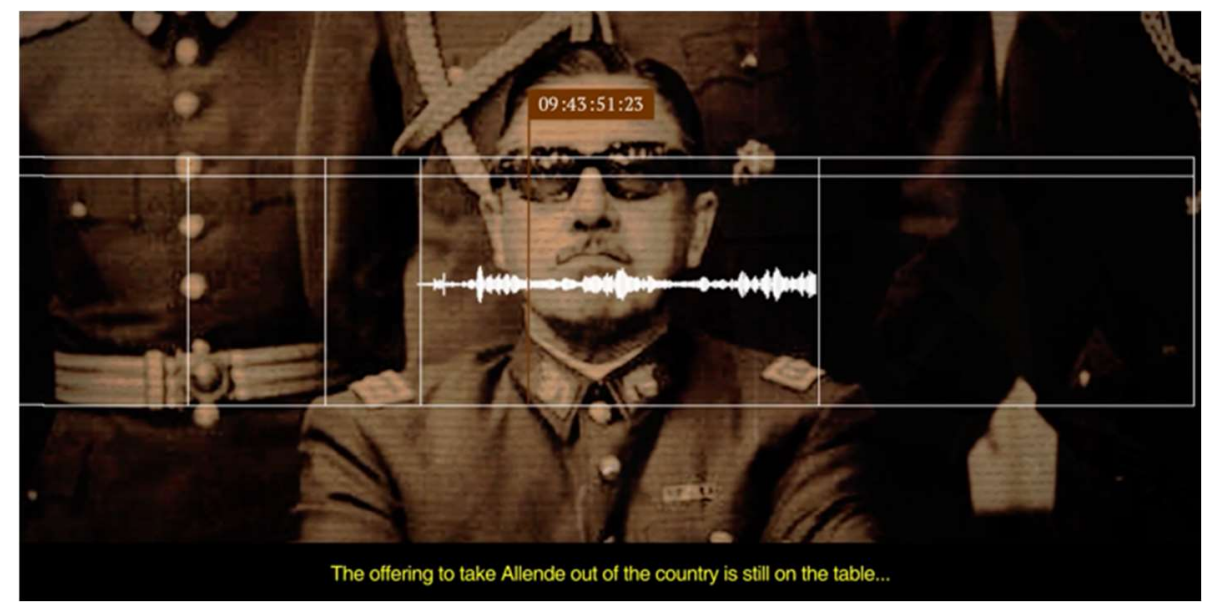

Fuente: Captura de video proyecto Sintoniza con la Memoria

Fig. 6 Gráfica video de proyecto.

Tal fue el impacto de la acción, que la transmisión fue escuchada y ampliamente comentada en redes por cerca de 4 millones de personas en 75 países, llegando a ser trending topic del día. Además, fue compartida durante la pauta programática y noticiosa de importantes medios nacionales, valorando lo emocionante e innovadora de la experiencia.

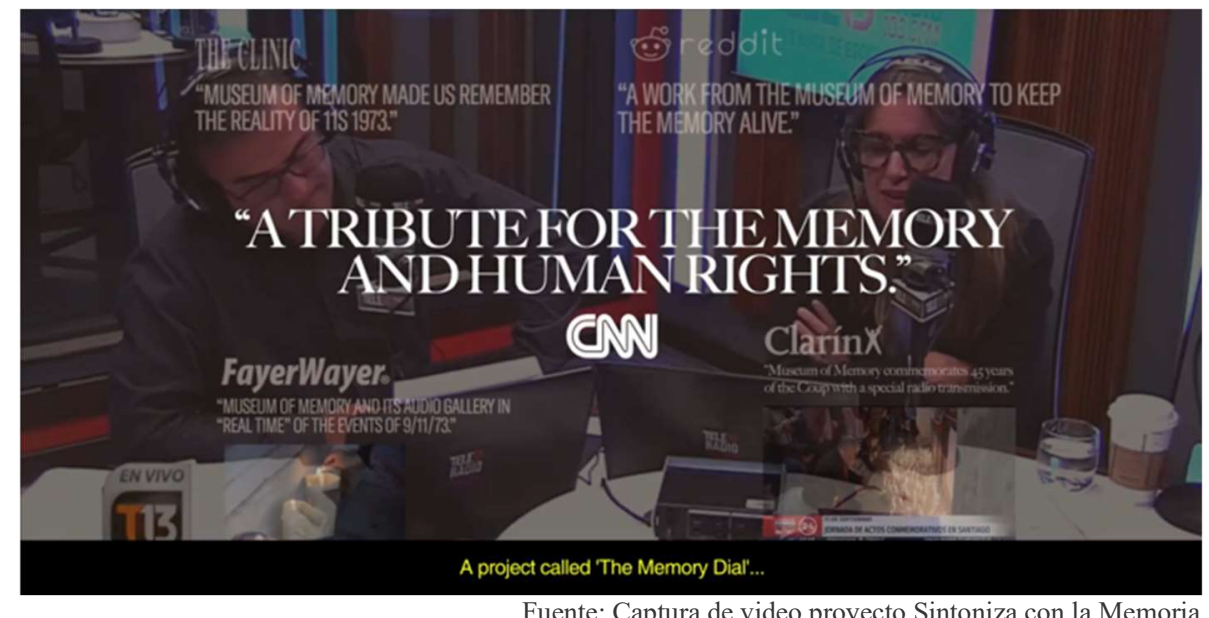

Fuente: Captura de video proyecto Sintoniza con la Memoria 


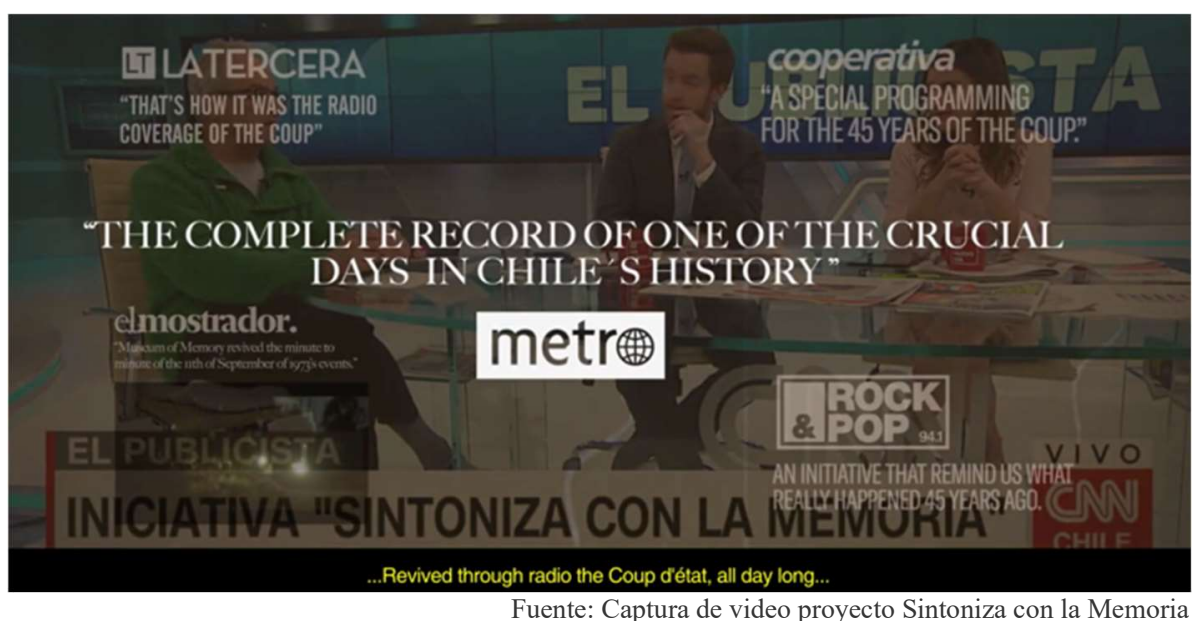

Fig. 7 y 8 Resumen de medios que cubrieron la transmisión

Este viaje sonoro al pasado se logró materializar gracias a un gran trabajo de investigación y la curaduría del material histórico, dirigido por una estrategia de contenidos y narrativa que logró construir una historia, generando una experiencia única, relevante y significativa. Ejercicio que podría ser replicado haciendo uso de cualquier otra colección documental.

El proyecto fue desarrollado junto al equipo de la agencia de publicidad Wolf BCPP y recibió importantes galardones como el León de bronce del Festival Internacional Cannes Lion 2019, el premio en la categoría Online y Apps, de Chile Diseño 2019; y Grand Prix y Oro en el Festival de Publicidad Achap 2018 (Chile).

Dado su alcance e innovación en el uso del patrimonio auditivo histórico que resguarda el Museo, esta acción se volvió a implementar en 2019 donde finalmente se consolidó como una propuesta permanente de la conmemoración del 11 de septiembre que realiza el Museo de la Memoria y los Derechos Humanos.

El archivo completo del proyecto está disponible en el sitio web: $\underline{\text { www.sintonizaconlamemoria.cl }}$

\section{Resultados}

La transmisión vía streaming logró ser escuchada por cerca de 4 millones de personas en 75 países. Esta cantidad de público equivale a 21 veces las visitas que el museo recibe en un solo año. La etiqueta \#A45AñosdelGolpe con la que se compartió la activación fue trending topic en Chile durante la jornada, lo que posicionó la programación conmemorativa del museo en un gran número de portales y medios de comunicación, nacionales e internacionales. Asimismo, la acción sumó sobre 20 mil nuevos seguidores a sus redes sociales. 
La experiencia fue ampliamente comentada y generó un espacio para reflexionar y discutir sobre este hecho que marcó la historia del país.

El museo también consiguió una impresionante visibilidad mediática durante el transcurso del día que se podría traducir en una inversión equivalente a más de 100 millones de pesos chilenos en publicidad.

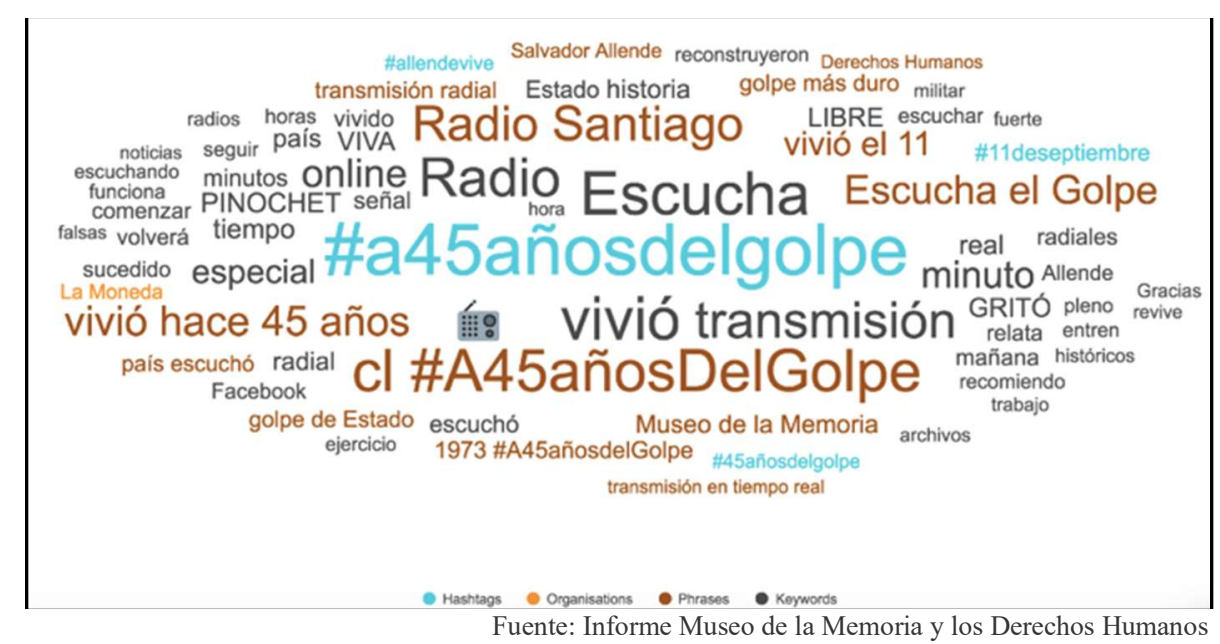

Fig. 9 Nube de términos más usados durante el 11 de septiembre de 2018

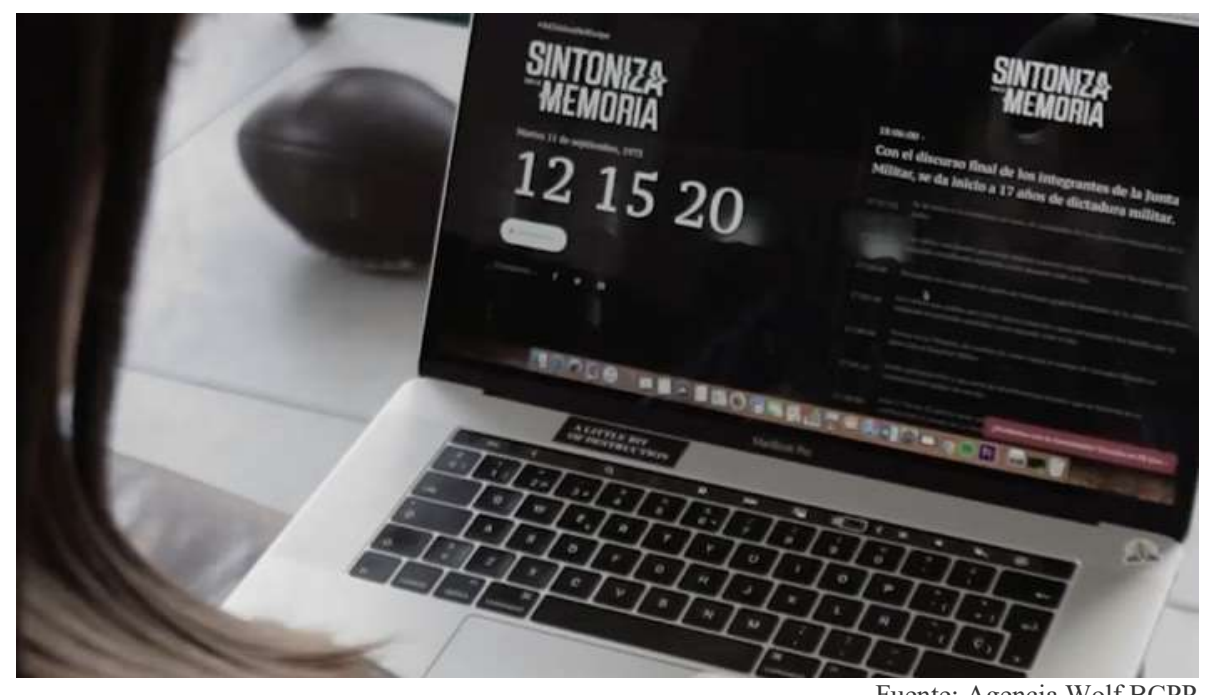

Fuente: Agencia Wolf BCPP

Fig. 10 Transmisión online 


\section{Conclusiones}

Las narrativas digitales o storytellings son estrategias de contenido tremendamente efectivas para espacios como los museos, donde ya existe un patrimonio que puede servir de base para la exploración y desarrollo de nuevos relatos. Esta forma de presentar los contenidos a la audiencia ofrece la posibilidad de crear experiencias en donde las personas se identifiquen, se involucren y participen en un nivel más profundo con las colecciones, en comparación con otros modelos más verticales de comunicación.

De la misma manera, este tipo de acciones representa una alternativa para potenciar nuevas dimensiones del trabajo de archivo y catalogación, que en la mayoría de los museos es una tarea permanente. El incorporar esta técnica de relato puede contribuir a crear nuevas interrelaciones, ayudando a explicar, profundizar o simplemente mostrar otras perspectivas sobre determinadas temáticas, mediante el uso de elementos multimediales, comunicacionales y digitales.

El storytelling es un recurso que aporta valor y ayuda a redescubrir formas de relacionarse con la audiencia. La condición digital de nuestra sociedad es un hecho innegable, por lo que el futuro de los museos también debería estar determinado por la comprensión de estos fenómenos sociales desde el ámbito conceptual, epistemológico, metodológico e ideológico.

La pandemia del Covid-19 reveló algunos retos actuales sobre el uso de medios digitales para los museos e impulsó rápidamente la adopción de tecnologías para hacer más accesibles sus contenidos para sus públicos virtuales. Hoy muchos museos, galerías y centros culturales a pesar de sus diferencias y presupuestos-, presentan una oferta de actividades y recursos que pueden llegar a una audiencia más amplia que nunca. En esa dirección y frente a un contexto post pandemia, será necesario repensar estrategias transmediales que consideren el comportamiento de usuarios mucho más conectados para la creación de nuevas experiencias.

Sintoniza con la Memoria es, sin duda, un excelente ejemplo de cómo generar una propuesta significativa utilizando recursos ya disponibles, y donde la clave de su impacto radica en la creación de un relato que organiza estratégicamente todos los elementos a modo de sinergia. El resultado de la nueva configuración es lo que es percibido como algo auténtico, ofreciendo una experiencia relevante que motiva al propio descubrimiento, a la exploración y a la construcción de significados a partir de las emociones. Y finalmente, todos estos factores son lo que ponen en relieve las colecciones.

Comparto algunos testimonios y comentarios que se recibieron en las diferentes plataformas:

\section{Comentarios al aire en medios de comunicación:}

"Me transportó al momento, a la escena, a esa radio que se escuchaba, a las persianas cerradas, a la angustia de mi mamá, a la angustia de mi abuela, a la incertidumbre de la suerte de mi papá. Es muy remecedor... muy remecedor.” 
"Es muy interesante el aporte de lo que hace el Museo de la Memoria. Es un ejercicio muy real"

\section{Comentarios en redes sociales:}

Marcela García García: Me duele el alma recordar cómo pasaron los aviones por sobre mi departamento en Monjitas, cómo se escuchó el bombardeo desde mi pieza, yo tenía 8 años y ¡no lo olvidaré jamás!

Camila González Fuentes: Por mi abuelo preso político, por la desolación de mi abuela, por el pueblo chileno con consciencia de clase que sufrió la desgarradora perdida de un ser amado. ¡Ni perdón ni olvido, justicia y verdad!

Wenche Farías Pinto: Yo era un niño y recuerdo haber escuchado en la radio los bandos. Y mi madre con una fotografía del presidente Allende lloraba amargamente.

Maritza Farías Cerpa: Gracias por este trabajo de memoria, para que quienes no estuvimos podamos escuchar lo que se transmitió ese día.

\section{Referencias:}

Ads of Brands. (2019, 15 marzo). Museum of Memory: The Memory Dial [Vídeo]. YouTube.

https://www.youtube.com/watch?v=KUz0Nv1ep8o\&ab_channel=AdsofBrands [Consulta: 12 de febrero 2021]

CHE, E. C. (2021, febrero 22-26). MuseumNext Digital Summit [Presentación online]. The Future Now: Digital Media in a Post-Pandemic World, MuseumNext Digital Summit, MuseumNext Digital Summit.

DÍAZ SALAMANCA, A. D., MORENO ROMERO, C. L., \& ROJAS, J. T. (2019). Relatos digitales museológicos en la comunicación social de la ciencia Estrategias narrativas innovadoras para salvaguardar el patrimonio de los museos capitalinos.

EUROPA, E. V. (2017, 9 octubre). Visitantes y Narrativa Digital. EVE Museos e Innovación. <https://evemuseografia.com/2017/10/09/visitantes-y-narrativa-digital/> [Consulta: 12 de febrero 2021]

EUROPA, E. V. (2017, julio 12). Museos y Narrativa. EVE Museos e Innovación. $<$ https://evemuseografia.com/2017/07/11/museos-y-narrativa/> [Consulta: 12 de febrero 2021]

JENKINS, H. (2015). Transmedia storytelling. In New Media Culture: Mediale Phänomene der Netzkultur (pp. 237-256). transcript-Verlag. 
ORTEGA, N. R. (2011). Discursos y narrativas digitales desde la perspectiva de la museología crítica. NÚMERO 4/DICIEM, 14.

SCOLARI, C. (2014). Narrativas transmedia: nuevas formas de comunicar en la era digital. Anuario AC/E de cultura digital, 1, 71-81.

Wolf BCPP. (2018, 5 octubre). Wolf / Museo de la Memoria / Sintoniza con la memoria. [Vídeo]. YouTube.

https://www.youtube.com/watch?v=uPft91IaRWg\&ab_channel=WolfBCPP/ [Consulta: 12 de febrero 2021] 